\section{2d ASBESTOS RELATED DISEASES IN EUROPE: TRENDS AND PERSPECTIVES}

IJ Rantanen, ${ }^{2} \mathrm{H}$ Wolff. 'University of Helsinki, Finland; ${ }^{2}$ Finnish Institute of Occupational Helsinki, Finland

\subsection{6/oemed-2018-ICOHabstracts.633}

Situation To date Europe has consumed about 50\% of the cumulative world asbestos production. Although 38 out of 53 European countries (72\%) have banned asbestos, 300 million Europeans still live with a potential risk of exposure.

Use and health outcomes Europe's takes $65 \%$ share of the yearly world asbestos production and 30.7\% share of consumption. A total of 30000 to 47000 ARD fatalities are estimated to occur in Europe including about $50 \%$ of all occupational cancer deaths. In the asbestos banning countries the ARDs increase; the non-banning countries record lower ARD rates.

Policies and practices Many European countries prohibited crocidolite and asbestos spraying in the early 1970s. Total bans were launched in 9 countries in the 1980s and the 1990s. The EU launched in 1983 protective and in 1999 preventive policies against asbestos. The EU asbestos ban came into force in 2005. The banning terminated the use of new asbestos, but protection of asbestos demolition workers is still a great challenge for which the EU has provided stringent regulations and guides. Policies from the WHO Regional Office for Europe and ILO cover all the 53 countries, including the 15 non-banning countries. The ILO and WHO Euro have called all countries to draw up national asbestos profiles, national programmes for elimination of ARDs and their better registration.

Proposals for further actions International Organisations, Global Coalition, EU and countries could jointly work for:

- Pan-European ban of asbestos

- Implementing the 'Freeing the EU from asbestos by 2030' initiative

- Information and support for safe alternatives

- Registration and labelling of sources, surveillance and registration of exposures and exposed workers

- Guidance in diagnosis and recognition of ARDs

- National programmes for:

- Elimination of exposures and for demolition

- Elimination of ARDs

- Capacity building, information, awareness raising.

\section{2e ASBESTOS IN LATIN AMERICA: PRESENT TRENDS IN PRODUCTION, CONSUMPTION AND POLICIES}

E Algranti, JP Ramos-Bonilla, B Terracini, V Santana, P Comba, R Pasetto, A Mazzeo, F Cavariani, A Trotta, D Marsili. Division of Medicine, FUNDACENTRO, São Paulo, Brazil

\subsection{6/oemed-2018-ICOHabstracts.634}

Situation Since asbestos has been banned in most industrialised countries, production and consumption have shifted to low and middle-income countries. At present, asbestos consumption in Latin America (LA) amounts to $10 \%$ of yearly global production. Brazil, the only LA producer, mined more than 7,000,000 tons of chrysotile between 1980 and 2013. Argentina, Chile, Honduras and Uruguay are the only LA countries where asbestos is banned and Brazil, Colombia and Mexico, the main consumers. The bulk of consumption is concentrated in asbestos-cement products.

Use and health outcomes In 2012 mortality from mesothelioma was in 5.6 and 1.0/1,000,000 in Argentina and Brazil, respectively. The few epidemiological studies available show clear evidences of clusters of mesothelioma in municipalities with a long history of asbestos consumption in Brazil and a forecast of rising incidence of mesotheliomas in Argentina and Brazil for the next decade. Employing a population attributable fraction method, a sizeable number of asbestos-related cancers was estimated for Argentina, Brazil, Colombia and Mexico.

Policies and practices The flawed arguments used by the industry to maintain its market, both to the public and in courtrooms, strongly rely on the lack of local evidences of ill effects and the invisibility of asbestos-related diseases in LA, due to limited number of studies and a difficult access of exposed workers to good quality health services. An inquiry made in Argentina, Brazil and Colombia disclosed only one internationally accredited laboratory for quantitative fibre analysis, doing only phase contrast microscopy.

Proposals for future actions In Brazil, non-governmental organisations of asbestos workers were pivotal to counter balance misinformation and inequities, ending recently in a Supreme Court decision to support eleven asbestos related state laws of prohibition, which, in practice, is curtailing asbestos mining. In parallel, continuous efforts should be made to stimulate the growth of competent and ethical researchers to convey adequate information to the scientific community and to the general public.

\section{$1722 \mathrm{f}$ ASBESTOS RELATED DISEASES IN THE UNITED STATES: HISTORICAL TRENDS AND CURRENT SITUATION}

${ }^{1}$ PJ Landrigan, ${ }^{2}$ RA Lemen. 'Arnhold Institute for Global Health, Icahn School of Medicine at Mount Sinai, New York, NY, USA; ${ }^{2}$ Department of Environmental Health, Rollins School of Public Health of the Emory University, Atlanta, USA

\subsection{6/oemed-2018-ICOHabstracts.635}

Asbestos use Asbestos was first discovered in the USA in 1825. Importation began in the mid-1800s and domestic mining in the 1890s. The industry grew in the 20th century and by the 1970s, over 700000 tons were consumed annually. Then, because of environmental and occupational restrictions coupled with vigorous efforts to seek legal compensation for injured workers, use declined. By 2000 annual consumption had fallen to 14600 tons, and most manufacturers had ceased production. However, the USA has never banned asbestos and still imports over 300 tons per year. Importation has recently increased. The chloralkali industry is the principal consumer. Asbestos-related disease Asbestos has caused over 200000 deaths in the USA. Multiple studies published between 1918 and 2000, most notably those of Irving Selikoff, documented the American ARD epidemic and linked asbestos to multiple cancers, mesothelioma in particular. The epidemic continues to the present, and in 2016 there were 2597 mesothelioma deaths, many in persons $<55$ years.

Prevention policies The first non-binding guidance on occupational asbestos exposure was proposed in the USA in 1938. The first regulation was established in 1972. In 1975, OSHA declared asbestos a human carcinogen. In 1979, OSHA and NIOSH declared that there is no safe level of exposure to asbestos. In 1989, EPA issued a rule banning most asbestoscontaining products, but this ban was overturned by the 